\title{
Predicados inacusativos e a modalidade deôntica
}

\section{Unaccusative predicates and deontic modality}

\author{
Núbia Ferreira Rech* \\ Giuseppe Freitas Varaschin ${ }^{*+*}$
}

Resumo

Esta pesquisa está embasada teoricamente na proposta de Hacquard (2006, 2010), para quem os modais são relativizados a eventos. Em relação aos deônticos, a autora assume a existência de dois tipos: ought-to-do, que acessam o evento VP; e ought-to-be, que acessam o evento de fala. De acordo com Pires de Oliveira e Rech (2016), o deôntico - tanto ought-to-do quanto ought-to-be tem que checar o traço [+Ag] com um dos participantes do evento ao qual está relativizado. Se essa hipótese estiver correta, é esperada uma restrição por parte de predicados inacusativos - que não selecionam argumento com propriedades de agente - a deônticos ought-to-do. Constatamos, entretanto, que inacusativos cujo argumento pode atuar nas fases preparatórias da eventualidade descrita no VP disponibilizam essa interpretação ao modal. Neste artigo, desenvolvemos uma proposta, a partir de Rothstein (2004), para explicar como esses inacusativos figuram com deônticos que são interpretados em posição baixa, em que a checagem do traço $[+\mathrm{Ag}]$ é feita com um participante do evento descrito pelo VP. A nossa solução foi postular uma estrutura de evento enriquecida para esses inacusativos, que têm em comum constituírem predicados de achievement relacionados a movimento em direção a um lugar físico (chegar, sair, entrar, aparecer, surgir...). Por fim, argumentamos - com base em diferenças relativas a aspecto e à seleção de um argumento que possa atuar nas fases preparatórias do evento - que nem todos os inacusativos apresentam uma estrutura enriquecida que permite sua interação com deônticos ought-to-do.

Palavras-chave: Deônticos ought-to-do, predicados inacusativos, estrutura incrementada.

\footnotetext{
* Agradecemos ao CNPq pelo incentivo a esta pesquisa através de auxílio financeiro (Processo 424025/ 2016-7).

** Universidade Federal de Santa Catarina

${ }^{\star \star \star}$ Universidade Federal de Santa Catarina
} 


\begin{abstract}
This research is theoretically based on a proposal by Hacquard (2006, 2010), according to which modals are relativized to events. Regarding deontics, she assumes a bipartite distinction: ought-to-do deontics, that access the event described by the VP; and ought-to-be deontics, that access the speech event. According to Pires de Oliveira and Rech (2016), both ought-to-do and ought-tobe deontics need to check a $[+\mathrm{Ag}]$ feature against one of the participants of the event to which they are relativized. If this hypothesis is correct, a restriction on unaccusative predicates on the part of ought-to-do deontics is expected, since they do not select an argument with agentive properties. We found, however, that unaccusatives whose arguments can act in the preparatory stages of the eventuality described by the VP do allow the modal an ought-to-do reading. In this article, we develop a proposal, based on Rothstein (2004), to explain how these unaccusatives are able to appear with low deontics, which check the [+Ag] feature on a participant of the event described by the VP. Our solution was to postulate an enriched event structure for these unaccusatives, which share the property of being achievement predicates related to a movement towards a physical location (arrive, leave, enter, appear, emerge...). Lastly, we argue - based on differences regarding aspect and the selection of an argument that can act in the preparatory stages of an event - that not all unaccusatives exhibit the enriched structure that allows for their interaction with ought-to-do deontics.
\end{abstract}

Keywords: Ought-to-do deontics, unaccusative predicates, incremental structure. 
N. B. ReCH \& G.

F. VARASCHIN

Predicados

inacusativos e

a modalidade

deôntica

\section{Introdução}

$\mathrm{N}$

este estudo, investigamos os predicados inacusativos em construções com modais deônticos. Nosso objetivo foi avaliar o papel que as propriedades dessas eventualidades sob o escopo do modal desempenham na sua interpretação. Abordamos a relação entre inacusativos e a modalidade deôntica, sob a perspectiva da existência de dois tipos de deônticos: ought-to-do, em que a obrigação ou permissão recai sobre o sujeito da sentença; e ought-to-be, em que a obrigação ou permissão recai sobre o interlocutor/addressee (cf. FELDMAN, 1986; BRENNAN, 1993; HACQUARD, 2006; PIRES DE OLIVEIRA; RECH, 2016). Partindo da hipótese - desenvolvida em Pires de Oliveira e Rech (2016) - de que os deônticos precisam checar o traço [+Ag] com um participante compatível na estrutura, o esperado seria que leituras deônticas baixas (ought-to-do), que checam o traço $[+\mathrm{Ag}]$ no evento de VP, não fossem possíveis com nenhum tipo de inacusativo.

O que notamos, todavia-e que já havia sido constatado experimentalmente em Pires de Oliveira e Rech (2016) -, é que essa expectativa não se confirma: embora alguns inacusativos (como morrer, (sobre)viver, cair e nascer) não possam figurar sob o escopo de deônticos ought-to-do, existem inacusativos que podem (como chegar, entrar, sair e aparecer). De acordo com nossa proposta, inspirada no trabalho de Rothstein (2004), isso ocorre porque estes últimos descrevem
Revista Letras,

Curitiba, UFPR, n. 96, pp.219-238, jul./dez. 2017. ISSN 2236-0999 (versão eletrônica) 
uma eventualidade que pode assumir uma forma enriquecida, denotando uma sequência incremental de eventos na qual atua um participante agentivo; dessa forma, o deôntico pode checar o traço $[+\mathrm{Ag}]$ no evento descrito pelo VP. O comportamento diferenciado dentre os inacusativos em relação ao deôntico do tipo ought-to-do sugere que essas eventualidades se repartem entre aquelas que podem ser controladas por um participante correferencial ao seu argumento, mediante o controle de suas fases preparatórias ( $x$ chegar), e as que não podem ( $x$ crescer), à semelhança do que se verifica nos predicados estativos: $x$ ser prudente vs $x$ ser alto (RECH; VARASCHIN, 2017).

Tanto para os estativos quanto para os inacusativos que coocorrem com deônticos ought-to-do, há evidências para a postulação de estruturas de eventos expandidas, nas quais o predicado lexicalizado figura apenas como um estágio final do processo. No caso de chegar, por exemplo, podemos pensar em uma estrutura enriquecida como uma sucessão de subeventos, por exemplo: sair de casa, pegar o carro, dirigir, abrir a porta e, enfim, chegar. Argumentamos que, por vezes, é possível localizar, nas fases iniciais (ou preparatórias) de tais estruturas, um participante $[+\mathrm{Ag}]$, que é capaz de satisfazer o requisito de agentividade dos deônticos em posição baixa.

Finalizamos o artigo levantando algumas hipóteses sobre quais propriedades comuns a um grupo de inacusativos - morrer, viver, cair, florescer - podem estar relacionadas às restrições que esses predicados oferecem à interpretação ought-to-do. Essa discussão aponta para desenvolvimentos que serão retomados em publicações futuras.

\section{A interface sintaxe-semântica e a interpretação dos modais}

Nossa análise está ancorada no modelo de Hacquard (2006, 2010), que prevê duas posições sintáticas diferentes para a checagem da base modal: no nível do VP e no nível do ato de fala. Essa proposta tem uma motivação similar àquelas que sublinham as diferenças de comportamento dos núcleos modais na interação com as categorias de tempo e aspecto (CINQUE 1999, 2006; STOWELL, 2004). Modais altos têm escopo sobre essas categorias, por isso seu tempo de avaliação é o momento da fala; modais interpretados em posição baixa ficam sob o escopo de tempo e da maioria das categorias de aspecto; a orientação temporal, neste caso, é provida por Tense (Tempo). Na hierarquia de Cinque (2006, p. 12), os epistêmicos correspondem a um núcleo alto; e os modais de raiz, a núcleos baixos, mais próximos do domínio lexical da sentença. Em (1), transcrevemos a parte relevante da hierarquia para o nosso estudo: 
N. B. Rech \& G.

F. VARASCHIN

Predicados

inacusativos e a modalidade

deôntica
(1) Hierarquia das Projeções Funcionais:

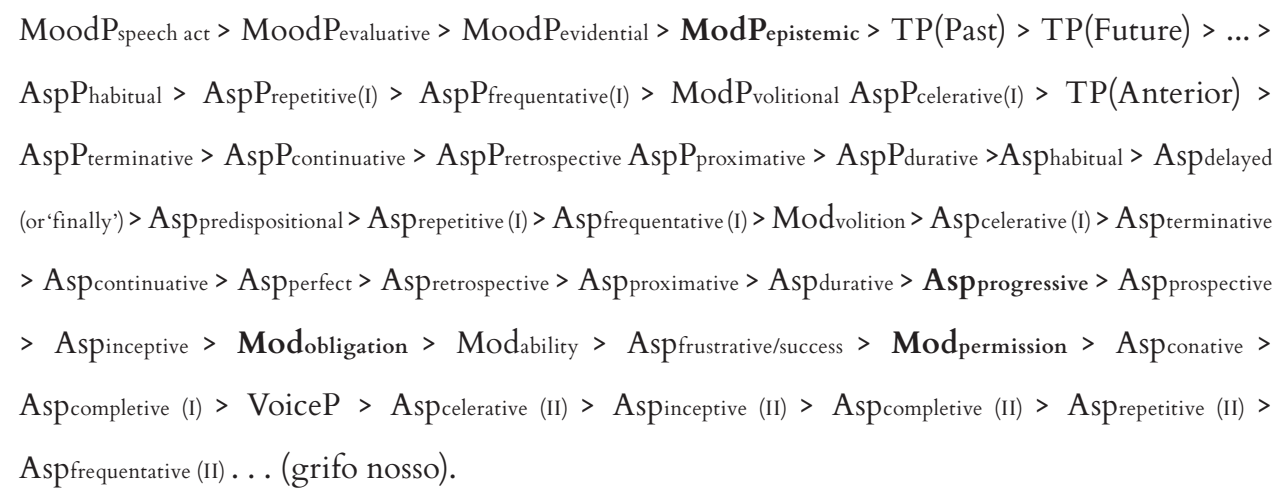

A hierarquia das projeções funcionais apresentada por Cinque levantou questões importantes para se pensar a representação dos modais. Para este autor, a interpretação de um modal está atrelada a determinada posição na estrutura da sentença.

A proposta de Cinque fez avançar os estudos sobre os núcleos modais no sentido de sinalizar um papel da sintaxe na sua interpretação. Essa abordagem prevê, a depender de como o núcleo interage com outras categorias funcionais, uma posição distinta na hierarquia para cada interpretação modal: $\operatorname{Mod}_{\text {Epistêmico, }}$ $\operatorname{Mod}_{\text {Voliç̃̃o }}, \operatorname{Mod}_{\text {Obrigação, }}, \operatorname{Mod}_{\text {Permissãa, }}, \operatorname{Mod}_{\text {Habilidade }}$ O tipo de modalidade está refletido de modo transparente na estrutura sintática (concebida aí de maneira enriquecida, o que é característico do projeto cartográfico), mais precisamente no local em que o modal figura na hierarquia de núcleos funcionais. Embora o autor não afirme que esses núcleos correspondam a itens lexicais distintos, as diferentes posições previstas na hierarquia sugerem uma distinção, mínima que seja, advinda do léxico. Além disso, o fato de que a interpretação do modal é um corolário da posição precisa que ele ocupa na estrutura implica uma discretização das categorias de modalidade. Essa discretização é rejeitada por abordagens como a de Kratzer (1981, 2001, 2012). Seu modelo tem, entre suas motivações principais, a meta de dar conta do fato de que, aparentemente, em diferentes línguas, os diversos tipos de modalidade são expressos por um conjunto relativamente restrito de itens lexicais. Os modais parecem ser universalmente polissêmicos e, para ela, a explicação para essa aparente polissemia não está em nenhum tipo de ambiguidade (seja ela lexical ou estrutural), mas sim no fato de que a semântica desses operadores é altamente dependente do contexto, envolvendo a saturação de variáveis como a de base modal e fonte de ordenação. Sua proposta semântica, entretanto, tal qual apresentada em Kratzer (1981, 2001, 2012), não explica a natureza das diferenças entre modais epistêmicos e de raiz em relação às categorias de tempo e aspecto, diferenças estas que foram descritas por Cinque (1999, 2006), entre outros.

A proposta de Hacquard (2006, 2010) busca, justamente, desenvolver um modelo que explique como um único item lexical assume distintas interpretações,
Revista Letras,

Curitiba, UFPR, n. 96, pp.219-238, jul./dez. 2017. ISSN 2236-0999 (versão eletrônica) 
se relacionando diferentemente com as categorias de tempo e aspecto. Esta é uma abordagem que se situa na interface entre a sintaxe e a semântica, combinando pontos das propostas de Kratzer e de Cinque. Diferentemente de Kratzer, Hacquard assume que modais são relativos a eventos de avaliação (e não a mundos), que atuam restringindo as situações às quais o modal se aplica:

modals are relative to an event - rather than a world - of evaluation, which readily provides a time (the event's running time) and (an) individual(s) (the event's participants). I propose that this event relativity of modals can in turn explain the correlation between type of interpretation and syntactic position, without having stipulation of an interpretationspecific height for modals. (HACQUARD, 2010, p. 80) ${ }^{1}$

O desafio que a proposta de Hacquard enfrenta é explicar como um mesmo item lexical pode assumir diferentes interpretações (epistêmica, deôntica, teleológica...) ao longo da derivação. À semelhança de Kratzer, ela assume tratar-se de um único item lexical, mas, para Hacquard, modais são relativos a um evento, e não a um mundo de avaliação. Esta autora especifica diferentes posições sintáticas que tornam disponíveis eventos com diferentes bases modais, conforme ilustrado em (2) e (3):

(2) a. John had to escape. ("João teve que escapar.") (Deôntico)

b. $\left[_{\mathrm{CP}}\right.$ speech e $0 \lambda \mathrm{e} 0\left[_{\mathrm{TP}} \mathrm{T}\left[\right.\right.$ AspP Asp1 $\lambda_{\mathrm{e}}\left[_{\mathrm{ModP}} \operatorname{Mod} f \mathrm{e}_{1}\right.$ [vP escape e1 ]]]]]

(3) a. John had to have escaped. ("João deve ter escapado.") (Epistêmico)

b. $\left[\right.$ speech e $0 \lambda \lambda_{\mathrm{e}} 0\left[_{\mathrm{ModP}} \operatorname{Mod} f \mathrm{e}_{0}\left[_{\mathrm{TP}} \mathrm{T}\left[_{\mathrm{AspP}}\right.\right.\right.$ Asp1 $\lambda \mathrm{e} 1$

[

(HACQUARD, no prelo, p. 7) $)^{2}$

Hacquard observa que a variável de evento precisa ser ligada localmente pelo elemento mais próximo. Os exemplos (2) e (3) mostram duas variáveis de evento às quais o modal pode se ligar: aspecto, como um quantificador sobre eventos, em (2b); e uma variável default, associada à projeção do ato de fala, em

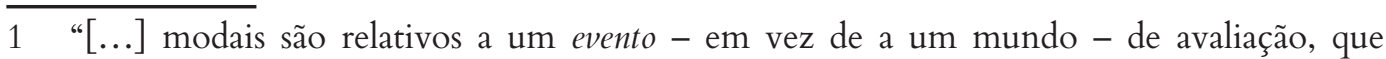
disponibiliza prontamente um tempo (o tempo corrente do evento) e um ou mais indivíduos (os participantes do evento). Proponho que essa relativização dos modais a eventos pode, por conseguinte, explicar a correlação entre o tipo de interpretação recebida e a posição sintática, sem que seja necessário estipular uma altura específica para a interpretação dos modais." (HACQUARD, 2010, p. 80, tradução nossa)

2 Hacquard apresenta ainda uma terceira alternativa de ligação do modal, quando este opera sobre o evento matriz em contextos de sentença encaixada:

(i) Mary thought that John had to have escaped.

'Mary pensou que John tinha que ter escapado.'

$\left[{ }_{\mathrm{CP}}\right.$ speech $\mathrm{e}_{0} \lambda \mathrm{e}_{0} \mathrm{~T}$ Asp ${ }_{2} \lambda \mathrm{e}_{2}$ think $\mathrm{e}_{2}\left[{ }_{\mathrm{CP}} \operatorname{Mod} f \mathrm{e}_{2}\left[{ }_{\mathrm{TP}} \mathrm{T}\right.\right.$ Asp1 $\lambda \mathrm{e} 1[\mathrm{VP}$ escape e1 $\left.\left.\left.]\right]\right]\right]$ 
N. B. ReCH \& G. F. VARASCHIN Predicados inacusativos e a modalidade deôntica (3b). Em (2), o modal está sendo interpretado em posição baixa, entre Asp e VP. A variável de evento mais próxima é o aspecto quantificando sobre o evento VP, então o modal opera sobre o evento descrito pelo VP, sendo orientado para um de seus participantes (John), o qual se realiza como sujeito da sentença. Em (3), o modal está sendo interpretado em posição alta, acima do núcleo TP. A variável de evento disponível para o modal é e0, que é associada ao ato de fala. O modal opera, então, sobre o evento de fala, sendo orientado para um de seus participantes; neste caso, o falante.

A proposta de representação de Hacquard, mostrada nos exemplos (2) e (3), dá conta de explicar como um único item lexical pode assumir diferentes interpretações - deôntica e epistêmica - ao longo da derivação a partir do tipo de variável de evento que o modal acessa. No modelo da autora, há três possíveis eventos que o modal pode acessar: o evento descrito pelo VP $\left(\mathrm{e}_{1}\right)$, conforme (2); o evento de fala $\left(\mathrm{e}_{0}\right)$, conforme (3); e o evento de atitude $\left(\mathrm{e}_{2}\right)$, que ocorre quando o modal aparece na posição alta de uma sentença encaixada sobre um verbo de atitude proposicional, como em (i), ilustrado na nota de rodapé 2 .

Sem dúvida, essa proposta constitui um avanço nos estudos dos auxiliares modais, ao manter a postulação de um único item lexical cujas diferentes interpretações são geradas ao longo da derivação pelo tipo de variável de evento com a qual o modal se combina. Este modelo - além de preservar as virtudes da abordagem contextual de Kratzer (2012) -, fornece uma explicação econômica para a distinção entre modais baixos (de raiz) e modais altos (epistêmicos). No entanto, não parece dar conta de uma distinção interna à classe dos deônticos: ought-to-do e ought-to-be (cf. FELDMAN 1986; BRENNAN 1993; HACQUARD 2006). Essas diferentes possibilidades de interpretação para o deôntico são ilustradas no exemplo a seguir:

(4) Os pacientes têm que tomar a medicação no horário especificado.

A sentença em (4) pode ser interpretada como: (i) de acordo com as normas da casa de repouso, a obrigação de tomar a medicação no horário especificado recai sobre os pacientes - deôntico do tipo ought-to-do; ou (ii) essa obrigação recai sobre o enfermeiro responsável pelos pacientes, por exemplo, que deve garantir que estes tomem a medicação no horário especificado - deôntico do tipo ought-to-be. No primeiro caso, a obrigação recai sobre um participante do evento descrito pelo VP (Os pacientes), que se realiza como sujeito da sentença; enquanto, no segundo caso, recai sobre o interlocutor (addressee), participante do evento de fala. Uma importante distinção entre os deônticos ought-to-do e ought-to-be é, portanto, o participante sobre o qual recai a orientação do modal.

Esses modais se distinguem também em relação ao tempo de avaliação. Em (4), a sentença está no tempo presente, podendo ser interpretada como o relato de uma ordem vigente - em que o modal recebe uma interpretação oughtto-do -, ou como um ato de fala performativo (uma ordem dada ao addressee) -
Revista Letras,

Curitiba, UFPR, n. 96, pp.219-238, jul./dez. 2017. ISSN 2236-0999 (versão eletrônica) 
em que o modal recebe uma interpretação ought-to-be. Como o tempo marcado pelo morfema flexional $\mathrm{T}$ coincide aí com o tempo de fala, essas duas leituras são possíveis para o deôntico. Por outro lado, se o modal estiver carregando marca de tempo passado, por exemplo, apenas a interpretação ought-to-do estará disponível, como se verifica em (5):

(5) Os pacientes tiveram que tomar a medicação no horário especificado.

A sentença (5) é uma asserção, enunciando uma obrigação que recaiu sobre Os pacientes. Neste caso, o modal está orientado para o sujeito da sentença, que corresponde a um dos participantes do evento VP; logo, tem-se uma interpretação deôntica do tipo ought-to-do. A interpretação ought-to-be não está disponível em (5): não é possível dar uma ordem - que constitui um ato de fala diretivo para que alguém realize um evento no passado. Nas sentenças em que o tempo de fala não corresponde ao tempo codificado pelo morfema de flexão temporal anexado ao modal, como em (5), o deôntico será, necessariamente, do tipo oughtto-do. Supomos que a restrição à interpretação ought-to-be ocorre nestes casos por ser este um deôntico alto, que não está sob o escopo das categorias $\mathrm{TP}_{\text {(Passado) }}$ e $\mathrm{TP}_{\text {(Futuro) }}$ o que o impede de realizar movimento (não se assume movimento para baixo na teoria) para acoplar-se à flexão $\mathrm{T}$.

É importante notar que o modelo de Cinque também não dá suporte para distinguir, estruturalmente, as duas interpretações associadas a ter que em (4), uma vez que prevê apenas uma posição para o deôntico de obrigação na hierarquia de núcleos funcionais - abaixo das categorias de tempo e próximo ao núcleo VoiceP (ver (1)). Tanto o modelo de Cinque quanto o de Hacquard permitem distinguir um deôntico baixo de um epistêmico - que corresponde a um modal alto, mas não um deôntico baixo (ought-to-do) de um deôntico alto (ought-to-be). Por essa razão, consideramos importante mapear as diferenças entre esses dois tipos de deônticos, tanto no plano semântico quanto sintático; dessa forma, supomos estar contribuindo para pensar a estrutura sintático-semântica desses auxiliares modais.

Esta pesquisa enfoca o emprego do deôntico do tipo ought-to-do em construções com predicados inacusativos. Com base na hipótese de Pires de Oliveira e Rech (2016), de que a interpretação deôntica é possível apenas quando o modal é relativizado a um evento com um participante agentivo, é esperado que, em construções inacusativas, não esteja acessível ao deôntico a interpretação do tipo ought-to-do, por não haver, no evento VP, um participante que porte o traço $[+\mathrm{Ag}]$. Nesse estudo, de natureza experimental, as autoras constataram, entretanto, que falantes do PB atribuíram ao deôntico a interpretação oughtto-do em construções com predicados inacusativos como chegar, sair, entrar, surgir, (des)aparecer, mas não com predicados como morrer, nascer, crescer, (sobre) viver, florescer... Os dados do experimento realizado pelas autoras revelaram uma separação no interior dessa classe: (i) inacusativos que figuram com deônticos 
N. B. ReCh \& G. F. VARASCHIN Predicados inacusativos e a modalidade deôntica

do tipo ought-to-do e ought-to-be; e (ii) inacusativos que disponibilizam para o deôntico apenas a interpretação do tipo ought-to-be (ver exemplos (6) e (7) na próxima seção). Em princípio, esses dados constituem um contra-argumento à proposta de Pires de Oliveira e Rech (2016). De acordo com essa proposta, a interpretação deôntica do tipo ought-to-do só será possível se houver no evento de VP um participante agentivo, o que ocorre em construções inergativas e transitivas, mas não em inacusativas. Na próxima seção, discutimos casos em que deônticos se combinam com diferentes inacusativos e, na sequência, propomos uma análise que dá conta de explicar como a interpretação deôntica do tipo ought-to-do é licenciada para alguns predicados inacusativos, como chegar, sair, entrar, surgir, (des)aparecer, mas não para outros, como nascer, cair, crescer, morrer, florescer.

\section{Predicados inacusativos e os tipos de deônticos}

Nós argumentamos que o modal deôntico pode ser interpretado tanto em posição baixa, sob o escopo das categorias de tempo, quanto em posição alta. Brennan (1993) e Hacquard (2006) assumem essa distinção entre os deônticos, observando que os do tipo ought-to-do são relativos ao evento descrito pelo VP; e os do tipo ought-to-be, ao evento de fala. É importante notar, entretanto, que a proposta dessas autoras, embora considere tal distinção entre os deônticos, não diferencia esses modais estruturalmente. Hacquard apresenta uma representação sintático-semântica para o deôntico, mas apenas para o do tipo ought-to-do (ver (2b) na seção 1).

Os trabalhos de Rech e Giachin (2014), Pires de Oliveira e Rech (2016) e Rech e Varaschin (2017) mostram que a interpretação deôntica do tipo oughtto-do é licenciada quando há, no VP, um participante agentivo. A partir desta constatação, foi desenvolvida a hipótese de que o deôntico precisa checar o traço [+Ag] com um dos participantes do evento ao qual está relativizado (PIRES DE OLIVEIRA; RECH, 2016). Supomos que a sintaxe desempenha um papel importante na interpretação dos modais, que parecem não ter sua leitura definida exclusivamente pelo contexto, a partir de uma base modal ordenada por uma fonte, conforme modelo de Kratzer (1981, 2001, 2012). Nossa proposta, a ser investigada nesta seção com predicados inacusativos, é compatível com o modelo de Hacquard (2006, 2010), que concebe os modais como relativos a eventos localmente acessíveis na estrutura das sentenças.

Considerando especificamente os deônticos, temos duas posições sintáticas - baixa e alta - para sua interpretação. Essas posições são definidas a partir das variáveis de evento disponíveis para o modal. Uma dessas variáveis de

Revista Letras,

Curitiba, UFPR, n. 96, pp.219-238,

jul./dez. 2017. ISSN 2236-0999 (versão eletrônica) 
evento é aspecto, que quantifica sobre o evento VP, então o modal é relativizado a este evento; outra é uma variável default, associada à projeção do ato de fala, o modal tem acesso, neste caso, ao evento de fala (ver seção 1). De acordo com nossa proposta, apenas o deôntico que se liga ao evento de VP - o do tipo oughtto-do - sofre restrições de natureza sintática. Se nossa hipótese estiver correta, a definição da leitura do modal sofre influência do evento descrito pelo VP, além da base modal e da fonte de ordenação, acessadas a partir da variável de evento, conforme a proposta de Hacquard (2006, 2010). O deôntico ought-to-be não está sujeito a esta restrição porque é interpretado em posição alta, acessando o evento de fala. Neste, há sempre um participante agentivo - o addressee - sobre o qual recai a orientação deste tipo de deôntico. Só está em questão, de fato, a presença de um participante agentivo no VP, pois, no nível do evento de fala, ao menos um participante agentivo (o addressee) já está sempre dado. Isso significa que, se não houver nenhum impedimento específico, a leitura ought-to-be estará sempre disponível para o deôntico (cf. RECH; VARASCHIN, 2017).

Considerando esse aporte teórico, passamos a analisar construções deônticas com predicados inacusativos. Pires de Oliveira e Rech (2016) realizaram um estudo de natureza experimental para avaliar se os falantes do português brasileiro $(\mathrm{PB})$ são sensíveis às propriedades do predicado encaixado quando atribuem interpretações deônticas ought-to-do. O experimento teve uma única variável independente, o tipo de verbo, com três níveis: (i) inergativos e transitivos, isto é, verbos que selecionam argumento externo (gritar, sorrir, abraçar, comer...); (ii) inacusativos cujo argumento pode atuar em fases preparatórias do evento descrito pelo verbo (chegar, sair, entrar, (des)aparecer...); e (iii) inacusativos cujo argumento não desempenha nenhum papel nas fases preparatórias do evento descrito pelo verbo (nascer, morrer, florescer, cair,...). O experimento considerou apenas o deôntico de obrigação deve. Os informantes tiveram de escolher, dentre três alternativas, a melhor interpretação para as sentenças, considerando o participante sobre o qual recai a orientação do modal: (a) a obrigação recai sobre o addressee; (b) a obrigação recai sobre o sujeito da sentença; ou (c) ambas as interpretações são possíveis. Os exemplos (6) e (7), a seguir, ilustram a tarefa do experimento com os dois grupos de inacusativos testados:

(6) O acusado deve morrer.
(a) A obrigação recai sobre o carrasco.
(b) A obrigação recai sobre o acusado.
(c) As duas possibilidades.

(7) O conferencista deve chegar cedo.
(a) A obrigação recai sobre o motorista.
(b) A obrigação recai sobre o conferencista.
(c) As duas possibilidades. 
N. B. ReCH \& G. F. VARASCHIN Predicados inacusativos e a modalidade deôntica
Revista Letras,

Curitiba, UFPR, n. 96, pp.219-238, jul./dez. 2017. ISSN 2236-0999 (versão eletrônica)
De acordo com a proposta das autoras - de que deônticos precisam checar o traço [+Ag] com um dos participantes do evento que acessam - seria esperada uma restrição à interpretação deôntica do tipo ought-to-do em ambos esses casos, dado que os verbos que aí figuram são inacusativos, que não selecionam tematicamente agentes. O experimento forçou uma interpretação deôntica, considerando que o objetivo foi avaliar se as propriedades do predicado encaixado ofereciam restrições à interpretação ought-to-do. Em relação à sentença em (6), o resultado foi o esperado: nenhum dos participantes atribuiu a interpretação descrita em (b) e (c), em que o acusado recebe a responsabilidade de ser agente do evento descrito em VP. Dentre as alternativas do experimento, a única possibilidade foi (a), em que a obrigação recai sobre o addressee, um participante agentivo do evento de fala. Por isso, a única interpretação deôntica licenciada neste caso foi a do tipo ought-to-be. Casos como o descrito em (7) receberam marcação significativa tanto na alternativa descrita em (b) quanto em (c), sugerindo que os falantes do $\mathrm{PB}$ percebem uma diferença no interior da classe inacusativa quando esses verbos estão sob o escopo de um deôntico. Parece que, de algum modo, os falantes interpretam que o sujeito de (7) pode ter algum controle (e, consequentemente, agentividade) na realização do predicado. Transcrevemos, abaixo, a tabela com o resultado geral do experimento das autoras:

\begin{tabular}{|l|l|l|l|}
\hline Tipo de verbo & NU & U+A & U-A \\
\hline $\begin{array}{l}\text { Agente externo } \\
\text { (interlocutor) }\end{array}$ & 18 & 35 & 123 \\
\hline Agente gramatical (sujeito da sentença) & 26 & 17 & 10 \\
\hline Ambos & 116 & 108 & 27 \\
\hline Total & 160 & 160 & 160 \\
\hline
\end{tabular}

Tabela 1 - Resultado do experimento de Pires de Oliveira e Rech (2016, p. 353)

Os resultados do experimento apontam que a maioria dos informantes escolheu a terceira alternativa - as duas possibilidades - para as sentenças com verbos não inacusativos (inergativos e transitivos) sob o escopo do deôntico: 116/160, na quarta linha e segunda coluna. Um resultado muito similar aparece nos contextos com inacusativos cujo argumento pode atuar nas fases preparatórias do evento (chegar, sair, entrar, (des)aparecer, surgir...): 108/160, na quarta linha e terceira coluna. O contraste está nas sentenças em que o deôntico figura com um inacusativo em que o argumento não atua nas fases preparatórias do evento (morrer, nascer, florescer...): 27/160, na quarta linha e quarta coluna. Para este último contexto, a preferência dos informantes foi a alternativa em que a obrigação recai sobre o addressee. Esses dados revelam que alguns verbos inacusativos - os

3 As siglas referentes à variável tipo de verbo apresentam o seguinte significado na Tabela: NU (non-unaccusative, i.e., não inacusativo) para identificar os predicados não inacusativos; $\mathrm{U}+\mathrm{A}$ (unaccusative [+agentivity], i.e., inacusativo [+agentividade]), para indicar os predicados inacusativos em que o argumento pode atuar em fases preparatórias do evento descrito pelo verbo; e, por fim, U-A (unaccusative [-agentivity], i.e., inacusativo [-agentividade]) indica os predicados inacusativos em que o argumento não desempenha nenhum papel nas fases preparatórias do evento descrito pelo verbo. 
identificados como U+A na tabela - se comportam de forma semelhante aos não inacusativos em relação a licenciar uma interpretação ought-to-do para o deôntico. O principal propósito do nosso estudo é buscar uma explicação mais rica para esse resultado, em que alguns inacusativos licenciam a leitura deôntica ought-to-do; enquanto outros oferecem restrição a esta interpretação. A chave para essa explicação, que será desenvolvida na seção seguinte, já está dada no modo como esse grupo de inacusativos foi caracterizado: eles apresentam um argumento que pode atuar - i.e. ser agente - nas fases preparatórias do evento descrito no VP.

As sentenças dos exemplos (6) e (7), repetidas a seguir como (6') e (7'), respectivamente, nos permitem observar diferenças na classe dos inacusativos quando estes figuram sob o escopo de um deôntico:

(6') O acusado deve morrer.

(7’) O conferencista deve chegar cedo.

Em (6'), o acusado não desempenha nenhum papel que contribua para a culminação do evento $\left[_{\mathrm{VP}} \mathrm{O}\right.$ acusado morrer]. A obrigação, neste caso, recai sobre um dos participantes do ato de fala: o addressee. A única interpretação deôntica possível para essa sentença é a de que o addressee recebe a ordem de um outro participante do ato de fala (o falante) para realizar algo que resulte na culminação do evento descrito no predicado sob o escopo do modal. Com esse tipo de predicado inacusativo, em que o argumento não atua em fases preparatórias do evento descrito na sentença, há uma restrição à interpretação deôntica do tipo ought-to-do, em que a orientação do modal recai sobre o sujeito.

A sentença em (7') pode ser empregada em um contexto no qual o falante dá a ordem para o addressee, que pode ser o motorista, para que o conferencista chegue cedo ao evento: leitura ought-to-be. ( $\left.7^{\prime}\right)$ pode, entretanto, ser enunciada em contextos nos quais a obrigação de chegar cedo ao evento recai sobre o conferencista. Isso porque o inacusativo chegar está figurando com um argumento que pode interferir no processo de culminação desse evento através da realização de eventos preparatórios como levantar às 6h30min, tomar café da manhã às $7 h 30$ min, pegar um táxi às $8 h$, etc. Uma vez que o conferencista é capaz, por si mesmo, de realizar um conjunto de eventos que resultem na sua chegada cedo a determinado local, faz sentido responsabilizar este participante pelo evento descrito em ( $\left.7^{\prime}\right)$. Nesta sentença, o modal pode, portanto, ser interpretado em posição alta - como um deôntico ought-to-be -, ou em posição baixa - como um deôntico ought-to-do.

$\mathrm{Na}$ próxima seção, nos ocupamos de explicar como a interpretação deôntica ought-to-do é possível com predicados inacusativos, mantendo nossa 
N. B. ReCh \& G. F. VARASCHIN Predicados inacusativos e a modalidade deôntica proposta de que o deôntico baixo precisa checar o traço [+Ag] com um dos participantes do evento VP.

\section{Proposta}

Os verbos inacusativos são, quase que por definição, entendidos como predicados que não atribuem papel temático de agente. Que alguns inacusativos possam figurar sob o escopo de deônticos ought-to-do é, portanto, um desafio para a nossa proposta geral, que postula que esse tipo de deôntico precisa encontrar um elemento agentivo na estrutura interna do evento denotado pelo VP. Se o argumento dos inacusativos nunca é agente, e se, ademais, não há qualquer outro participante agentivo em sua grade temática, com qual elemento da estrutura os deônticos estariam checando o traço [+Ag], de modo a tornar a leitura ought-to-do de (7’) disponível?

Nossa hipótese, que está baseada na análise que Rothstein (2004) faz dos achievements ${ }^{4}$ no progressivo, envolve a postulação de uma estrutura de evento incrementada para inacusativos sob o escopo de um deôntico ought-todo. A ideia geral é que a eventualidade codificada pelo VP assume uma forma enriquecida, de modo a denotar uma sequência incremental de eventos, na qual o evento lexicalizado indica o ponto de culminação. Esses outros eventos, que descrevem fases preparatórias do achievement inacusativo, podem ter um agente correferencial ao argumento do predicado inacusativo. É com este participante agentivo, que integra a estrutura incrementada do VP, que o deôntico baixo (ought-to-do) vai checar o traço [+Ag] em sentenças como (7’). Nesses casos, então, não é propriamente o argumento do predicado inacusativo que satisfaz a necessidade de agentividade do deôntico, mas sim um argumento correferencial a ele em uma série de eventos preparatórios que culminam no predicado inacusativo original.

O foco deste artigo é explicar a possibilidade da interpretação oughtto-do com predicados inacusativos, mas consideramos importante também discutir por que alguns membros dessa classe oferecem restrição a este tipo de deôntico. Isto é, cabe explanar por que inacusativos como morrer, nascer, cair, etc. não se comportam, no que tange às interações com operadores modais, como os inacusativos chegar, sair, aparecer, etc. Essa abordagem será apresentada com detalhamento em produção futura, mas nossa argumentação seguirá na linha de que essa diferença diz respeito a características específicas dessas eventualidades e, em particular, a modo como elas se relacionam com as atividades que são capazes de produzi-las.

4 De acordo com o entendimento tradicional (cf. VENDLER, 1967), achievements são eventualidades dinâmicas, télicas e não-durativas.
Revista Letras,

Curitiba, Ufpr, n. 96, pp.219-238, jul./dez. 2017. ISSN 2236-0999 (versão eletrônica) 
Passemos aos casos de inacusativos que funcionam com deônticos oughtto-do. Em uma das interpretações disponíveis para a sentença (8) abaixo, a orientação do modal recai sobre o sujeito (a bailarina), que é argumento interno de um predicado inacusativo:

(8) A bailarina tem que sair do palco no início do segundo ato.

Com esta interpretação, o inacusativo está sob o escopo de um deôntico ought-to-do. Nossa hipótese é que, nesses casos, o evento ao qual o modal está relativizado apresenta fases preparatórias em que a bailarina - argumento do inacusativo - pode atuar. Assim, o mesmo participante - a bailarina - pode receber marcação temática de agente de um evento preparatório, como deslocar-se até o local atrás da cortina, e de tema do evento sair do palco. A ação de deslocamento pode ser entendida como um estágio de um accomplishment ${ }^{5}$ derivado que tem o achievement lexical sair do palco como ponto de culminação. A fim de definirmos com mais rigor a noção de culminação, precisamos definir (ainda que não de maneira exaustiva) as noções de estágio e de continuação. Adaptamos essas duas definições de Rothstein (2004, p. 46) e acrescentamos ao fim nossa definição de culminação:

(i) Estágio: Um evento e é um estágio de um evento e'se e somente se e se desenvolve em $e^{\prime}$.

(ii) Continuação: Seja e um evento que ocorre em um tempo t. Seja $e^{\prime}$ um evento que ocorre em um tempo $t$ ', onde $t$ é um subintervalo de $t^{\prime}$. $e^{\prime}$ é uma continuação de $e$ se e somente se $e$ for um estágio de $e$ '.

(iii) Culminação: Um evento $e$ 'é a culminação de um evento $e$ se e somente se $e^{\prime}$ for uma continuação de $e$ e não houver nenhum outro evento posterior a $e$ ' que seja uma continuação de $e$.

Uma das interpretações disponíveis para a sentença em (8) é aquela em que a orientação do modal recai sobre o sujeito da sentença (ought-to-do). Para gerar essa leitura, o significado lexical do predicado inacusativo deve estar incorporado a uma estrutura de evento enriquecida (que corresponde ao evento descrito pelo VP acessível ao modal), onde ele deixa de ser um puro achievement e passa a funcionar como a culminação pontual de um evento durativo e' que apresenta as características de uma espécie de accomplishment.

Os accomplishments, caracteristicamente, apresentam, em sua estrutura subeventual, estágios de atividade ou estágios de processo, segundo a terminologia de Landman (1992). Estágios de atividade ou de processo de um dado evento $e$ '

5 De acordo com Vendler (1967), accomplishments são eventualidades compostas por estágios sucessivos e que apresentam duração intrínseca: [+durativos] e [+télicos]. Accomplishments e achievements são categorias muito semelhantes à medida que correspondem a eventos dinâmicos e télicos; diferenciam-se, entretanto, pelo traço pontualidade: achievements são [-durativos] e accomplishments são [+durativos]. 
N. B. ReCH \& G. F. VARASCHIN Predicados inacusativos e a modalidade deôntica são simplesmente estágios de $e^{\prime}$ que são atividades ou processos, nos termos de Vendler (1967). Se em (8) o predicado for modulado em um accomplishment, a bailarina, mesmo não sendo agente da culminação de $e$ ' - i.e. do estágio final do accomplishment derivado em (8) -, pode ser agente de seus estágios de atividade, como, por exemplo, os eventos de andar, deslocar-se até o local atrás da cortina e de esconder-se nos fundos do palco. Algo semelhante ocorre com o exemplo (7') da seção 2, no qual o conferencista, mesmo não sendo agente do achievement inacusativo chegar, pode ser agente de estágios de atividade que surgem em uma estrutura incrementada desse achievement em um accomplishment. A presença de um participante agentivo na estrutura incrementada de VP satisfaz o requisito de agentividade de um deôntico, disponibilizando, assim, a interpretação oughtto-do.

Os VPs inacusativos que figuram sob o escopo de deônticos ought-todo são, portanto, achievements incrementados, que assumem uma estrutura de evento similar à dos accomplishments, que comportam uma fase de atividade e uma fase final, de culminação. Como eles dispõem de agentes possivelmente correferenciais ao argumento do inacusativo nas fases de atividade, podem funcionar com deônticos ought-to-do. $\mathrm{O}$ achievement original corresponde à culminação do accomplishment derivado. A diferença aí é que a fase de atividade não está lexicalmente especificada, uma vez que o conjunto de atividades que culminam nos eventos não é fixo e nem previsível (cf. ROTHSTEIN, 2004, p. $55-56)$.

A ideia de que os achievements podem assumir uma estrutura de evento enriquecida segundo a linha que indicamos acima não é totalmente nova. A mesma ideia é defendida por Rothstein (2004) para explicar a possibilidade de achievements no progressivo. Com efeito, todos os inacusativos que funcionam com leitura ought-to-do aceitam também a perífrase progressiva, como vemos em (9) abaixo:

(9) a. O conferencista está chegando.

b. A bailarina está saindo do palco.

c. Os intelectuais estão desaparecendo da cena pública.

Supomos que a descrição do processo de enriquecimento da eventualidade em estruturas com deôntico ought-to-do deva ser um pouco mais específica que a de eventualidades que figuram com o progressivo, cuja descrição é proposta por Rothstein (2004, p. 49). Conforme essa autora, o progressivo exige que a eventualidade sobre a qual ele opera apresente estágios que culminem no evento que é denotado por VP. ${ }^{6}$ Quando o evento sob o escopo do progressivo é um achievement, a autora assume uma estrutura enriquecida semelhante 6 Uma asserção com a forma ' $x$ está VP-ndo' é verdadeira se e somente se há um evento e ocorrendo que é estágio de um evento e', onde e' é a denotação de VP. (ROTHSTEIN, 2004, p. 45 , tradução nossa)
Revista Letras,

Curitiba, UFPr, n. 96, pp.219-238, jul./dez. 2017. ISSN 2236-0999 (versão eletrônica) 
à que postulamos aqui: o achievement passa a ser visto como a culminação de um accomplishment derivado, no qual o progressivo captura seus estágios preparatórios, seja lá qual for sua natureza.

Já quando o achievement está sob o escopo de um deôntico ought-to-do, não basta que tenhamos uma estrutura enriquecida com estágios preparatórios; estes têm que apresentar um agente correferencial ao tema do predicado inacusativo, que passa a funcionar como culminação, como ocorre em (7') e (8). A formalização da estrutura dessas eventualidades será, naturalmente, semelhante àquela que Rothstein (2004, p.138) propõe para os achievements progressivos. A diferença mais relevante é que, para o caso de achievements inacusativos sob o escopo de deônticos ought-to-do, o tema do predicado inacusativo não pode ser mero tema dos estágios de atividade, mas tem que ser seu agente.

Observamos, na seção 2, que inacusativos como morrer, nascer, cair, florescer e sobreviver não ocorrem sob o escopo de deônticos ought-to-do. Este parece ser um comportamento previsível e natural tratando-se de verbos inacusativos. Vimos, entretanto, nesta seção, que o fato de termos um predicado inacusativo não impede que o modal seja interpretado em posição baixa, como um deôntico ought-to-do. A questão que cabe discutir é, então, por que essa estrutura não pode se aplicar a todos os inacusativos, como sugerem as restrições que alguns membros dessa classe impõem à interpretação deôntica do tipo ought-to-do.

Primeiramente, cabe observar que os inacusativos que figuram com deônticos ought-to-do são todos achievements: chegar, sair, entrar, surgir, (des-) aparecer...; ao passo que aqueles que oferecem restrições a essa interpretação, não: viver, sobreviver, crescer, florescer... Estes últimos descrevem processos e, enquanto tais, denotam diretamente uma eventualidade durativa, sem precisar de qualquer tipo de incrementação. Como eles não comportam estágios de atividade ou qualquer tipo de subevento agentivo, eles não apresentam um agente na estrutura de VP que possa atender às exigências dos deônticos ought-to-do.

Casos mais desafiadores são aqueles como o do predicado morrer, classificado como um achievement por muitos autores (cf. DOWTY, 1979; FILIP, 1999; ROTHSTEIN, 2004). Admitimos que esse verbo pode assumir, em alguns casos, uma estrutura enriquecida similar à de um accomplishment ${ }^{7} .{ }^{\mathrm{E}}$ importante notar, entretanto, que, mesmo nesses casos, morrer não licencia para o modal a interpretação deôntica do tipo ought-to-do, diferenciando-se, assim, de predicados como chegar, entrar, aparecer. Essa restrição parece estar relacionada à impossibilidade de um agente correferencial ao argumento do inacusativo morrer atuar em seus estágios de processo. Isso fica claro em (10):

\section{(10) O acusado deve morrer.}

7 Isso fica claro quando notamos que esse verbo é, bem como os inacusativos que aceitam leituras ought-to-do, aceitável no progressivo: "O acusado está morrendo de câncer." Rothstein (2004) argumenta que a função semântica do progressivo é justamente focar nos estágios preparatórios de uma eventualidade, conforme nossa proposta. 
N. B. ReCh \& G. F. VARASCHIN Predicados inacusativos $e$ a modalidade deôntica

Mesmo que tenhamos aí uma estrutura de evento incrementada - o que parece ser o caso, na qual o inacusativo morrer é culminação de um accomplishment derivado, o agente dos seus possíveis estágios de atividade não corresponde a um participante do evento VP. O experimento de Pires de Oliveira e Rech (2016) mostra que, para estes casos, os informantes assinalaram que a obrigação recai apenas sobre o addressee - participante do evento de fala. Logo, o deôntico não pode ser interpretado em posição baixa pela falta de um participante agentivo no nível VP que possa atuar em fases preparatórias do achievement morrer ${ }^{8}$. Daí a restrição do inacusativo morrer a deônticos ought-to-do.

Por fim, outra distinção entre os inacusativos que licenciam e os que restringem a interpretação ought-to-do envolve a noção de deslocamento físico, verificada apenas nos primeiros. Esse ponto foi assinalado por Rothstein (2004, p. 141):

For verbs of motion, such as reach the top of the mountain, arrive at the station and so on, the witness event must include an activity event whose characteristics are not specified, and a BECOME event which is an event of moving toward the physical location at which the culmination can take place. ${ }^{9}$

O deslocamento físico que parece ser acarretado por estes verbos torna os estágios de atividade do evento salientes e, consequentemente, facilita a identificação de um agente que possa ser correferencial ao tema do inacusativo. O agente em questão pode ser o agente do deslocamento que está implícito no próprio inacusativo.

Para verbos que não envolvem movimento através de um local físico, como morrer, a presença de um evento de atividade que resulte no achievement é uma possibilidade, mas não parece ser uma necessidade, como no caso de verbos como chegar, sair, entrar. Não há nada que indique que tipo de estágio de atividade pode dar origem a um predicado como morrer, diferentemente do que ocorre com predicados como chegar, em que a ideia de deslocamento já sugere atividades. Predicados inacusativos como chegar acarretam eventos de deslocamento - os quais, claramente, podem ter agentes correferenciais ao argumento do inacusativo -, o que não ocorre com predicados como morrer e nascer. Retomaremos este ponto em publicação futura, a fim de averiguar com maior detalhamento a razão

Revista Letras,

8 Nossa análise não está considerando contextos como o de teatro, por exemplo, em que é possível responsabilizar um dos atores pela eventualidade descrita por um inacusativo [-agentividade]: 'O bobo da corte deve cair no final do II Ato', 'A princesa deve desmaiar ao morder a maçã' ou, ainda, 'O rei Lear deve morrer no Último Ato'. Isso porque esses predicados não estão sendo empregados como inacusativos nesses contextos, visto que não se trata da realização dessas eventualidades, e sim de sua simulação. Para simular uma queda, um desmaio ou uma morte, é necessário um participante com o traço $[+\mathrm{Ag}]$.

9 Para verbos de movimento, como alcançar o topo da montanha e chegar na estação, o evento testemunhado deve incluir um evento de atividade (cujas características não são especificadas) e um evento BECOME, que é um evento de movimento em direção ao lugar físico no qual a culminação ocorre. (ROTHSTEIN, 2004, p. 14, tradução nossa)

Curitiba, UFPR,

n. 96, pp.219-238,

jul./dez. 2017. ISSN 2236-0999

(versão eletrônica) 
pela qual alguns inacusativos - a despeito de poderem assumir uma estrutura enriquecida - oferecem restrições à interpretação ought-to-do.

\section{Considerações finais}

Os inacusativos fornecem evidências interessantes para quem busca averiguar se a estrutura interna dos predicados verbais pode contribuir com a definição das categorias de modalidade. Dadas algumas suposições tanto sobre a natureza dos inacusativos quanto sobre a dos modais deônticos (que foram o foco da nossa pesquisa), uma das consequências esperadas, no início dessa investigação, era que os inacusativos só aparecessem sob o escopo de deônticos ought-to-be, visto que não selecionam agente.

Essa hipótese não ganha sustentação nos dados do experimento realizado por Pires de Oliveira e Rech (2016). Passamos, então, a focar nossa atenção em construções com inacusativos sob o escopo de deônticos ought-to-do. Desenvolvemos, a partir de Rothstein (2004), uma proposta que, no nosso entender, dá conta de explicar como inacusativos podem licenciar a interpretação deôntica do tipo ought-to-do ao modal. A nossa solução - de postular uma estrutura de evento enriquecida para achievements inacusativos - nos colocou em uma situação inversa àquela que estávamos no início da pesquisa. O desafio passou a ser, então, como explicar o fato de nem todos os achievements inacusativos poderem assumir o tipo de estrutura de evento enriquecido que permite a interação com deônticos ought-to-do. Insinuamos aqui apenas os primeiros passos de uma resposta a essa questão. 
N. B. ReCh \& G.

F. VARASCHIN

Predicados inacusativos e a modalidade

deôntica

\section{Referências}

BRENNAN, VIRGINIA MARY. Root and Epistemic modal auxiliary verbs. 1993. 455 fls. Ph.D. Thesis, University of Massachusetts, Amherst, 1993.

CINQUE, GUGLIELMO. Restructuring and Functional Heads. The Cartography of Syntactic Structures. Vol.4. NY: Oxford University Press, 2006.

CINQUE, GUGLIELMO. Adverbs and Functional Heads: a cross-linguistic perspective. New York: Editora Oxford University Press, 1999.

DOWTY, DAVID. Word Meaning and Montague Grammar. Dordrecht: Reidel, 1979.

FELDMAN, FRED. Doing the Best We Can. Dortrecht: Reidel, 1986.

FILIP, HANA. Aspect, eventuality types and nominal reference. New York: Garland, 1999.

HACQUARD, VALENTINE. Aspects of modality. 2006. 214fls. Tese de Doutorado. Massaschusetts Institute of Technology, Cambridge, 2006.

HACQUARD, VALENTINE. On the Event Relativity of Modal Auxiliaries. Natural Language Semantics, 18(1), p. 79-114, 2010. Disponível em: <http://ling. umd.edu// hacquard/papers/hacquard_NALS_eventrelativity.pdf $>$. Acesso em 12 de janeiro de 2017.

HACQUARD, VALENTINE (NO PRELO) MODALS: MEANING CATEGORIES? IN: NEW APPROACHES TO TENSE, ASPECT AND $M O O D$. University of Chicago Press. Disponível em: <http://ling.umd. edu// hacquard/papers/Hacquard_mmc_preprint.pdf $>$. Acesso em 12 de janeiro de 2017.

KRATZER, ANGELIKA. The notional category of modality. In: EIKMEYER, H-J.; RIESER, H. (Orgs.) Word, worlds, and contexts: new approaches to word semantics. Berlin: W. de Gruyter, 1981. p. 38-74.

KRATZER, ANGELIKA. Modality. In: VON STECHOW, A.; WUNDERLICH, D. (Orgs.) Semantik: Ein internationales Handbuch zeitgenössischer Forshhung. Berlin: Mouton de Gruyter, 2001. p. 639-650.

KRATZER, ANGELIKA. Modals and Conditionals. New York: Oxford University Press, 2012.

LANDMAN, FRED. The progressive. Natural language semantics, v. 1, n. 1, p. $1-32,1992$.

PIRES DE OLIVEIRA, ROBERTA; RECH, NÚBIA S. Ferreira. Flavors of obligation: the syntax/semantics of deontic deve in Brazilian Portuguese. Letras de Hoje, v. 51 n. 3), p. 349-357, 2016.
Revista Letras,

Curitiba, UFPR,

n. 96 , pp.219-238,

jul./dez. 2017.

ISSN 2236-0999

(versão eletrônica) 
RECH, NÚBIA S. Ferreira; GIACHIN, Amanda. As interpretações disponíveis para os modais pode e deve em construções com predicados adjetivais. ReVEL, edição especial n. 8, p. 21-49, 2014.

RECH, NÚBIA S. Ferreira; VARASCHIN, Giuseppe. Predicados estativos e os tipos de deôntico: ought-to-do e ought-to-be. 2017. [Circulação restrita].

ROTHSTEIN, SUSAN. Structuring Events: a study in the semantics of lexical aspect. Oxford: Blackwell Publishing, 2004.

STOWELL, TIM. Tense and modals. In GUÉRON, J.; LECARME, J. (Orgs.) The Syntax of Time. Cambridge, Massachusetts: The MIT Press, 2004. p. 621635.

VENDLER, ZENO. Verbs and times. In: Linguistics in philosophy. Ithaca: Cornell. University Press, 1967. p. 97-121.

Submetido em: 25-01-2017

Aceito em: 06-06-2017 